\title{
НЕКОТОРЫЕ АСПЕКТЫ РАЗВИТИЯ УЧЕТА, АНАЛИЗА И АУДИТА В РАМКАХ ЕДИНОЙ ИНФОРМАЦИОННОЙ СИСТЕМЫ
}

\section{(c) 2019 Петров Александр Михайлович}

доктор экономических наук, профессор Департамента учета, анализа и аудита Финансовый университет при Правительстве Российской Федерации, Россия, Москва E-mail:palmi@inbox.ru

\section{(c) 2019 Лавров Денис Анатольевич}

начальник Управления координации научных исследований Финансовый университет при Правительстве Российской Федерации, Россия, Москва Email:DALavrov@fa.ru

В статье рассматриваются такие аспекты развития учета, анализа и аудита в рамках единой информационной системы, как влияние потоков информационного взаимодействия в компании в учетно-аналитической сфере; исследуются основные программы, применяемые в бухгалтерском учете и отчетности; обосновывается необходимость учета уровня программного обеспечения; анализируется зависимость информационных систем бухгалтерского учета от масштаба компании.

Ключевые слова: циифровизация; развитие учета, анализа и аудита; единая информационная система.

В настоящее время осуществляется переход к цифровизации экономических процессов, которая является катализатором мирового общественного развития и обеспечивает рост эффективности экономики и повышение качества жизни.

Цифровая экономика ставит задачу реформирования учета, анализа и аудита в рамках формирования единой информационной системы, и основную роль в этом процессе играют такие факторы, как автоматизация учета, применяемые программные средства, информационные программы, информационное пространство субъектов хозяйствования, и изменения экономической ситуации, в которой они функционируют.

Информационные технологии широко применяются в бухгалтерском учете.

Федеральный закон от 27 июля 2006 года № 149-Ф3 «Об информации, информационных технологиях и о защите информации» [5], информационные технологии рассматривает в качестве процессов, а также способов осуществления поиска, сбора, хранения, обработки, предоставления, распространения информации.

Информационные технологии служат цели интенсификации процессов и совершенствования системы применения информации при реализации многих видов экономической деятельности, и при осуществлении бухгалтерского учета и аудита также активно используют данные технологии.

Рассмотрим основные аспекты влияния цифровизации общества и экономики на сферу бухгалтерского учета и аудита:

1. Пересмотр роли отчетности в новой системе хозяйствования с учетом вызовов глобализации;

2. Совершенствование методики сбора, обработки и предоставления информации о деятельности субъектов хозяйствования, отвечающей веяниям цифровизации;

3. Наличие практического интереса предпринимательского сообщества в предоставлении достоверной информации об экономической деятельности и существование высоко профессиональных кадров, готовых формировать подобную отчетность;

4. Формирование системы управления на правительственном уровне, а также на уровне хозяйствующих субъектов, нового подхода развития учета, анализа и аудита с учетом современных условий. Необходимость определения целей, направлений и мер политики по созданию необходимых условий внедрения цифровизации, как правовых, технологических, организационных, так и финансовых;

5. Учет высокой капиталоемкости мер политики внедрения цифровизации в финансовую сферу, бухгалтерский учет; 
6. Модифицирование процессов производства, их ускорение, сокращение производственных циклов, снижение постоянных расходов, которые в настоящее время занимают существенную долю в общих затратах на производство;

7. Расширение использования в бухгалтерском учете, анализе и аудите инструментария цифровизации с целью расширения мирохозяйственных связей, нацеленных на устойчивое развитие социально-экономических и экологических систем.

Большую роль в становлении цифровизации учета играют информационные потоки, представляющие совокупность экономической, финансовой, и иной информации, необходимой для осуществления функций управления, анализа и оценки деятельности хозяйствующих субъектов. На рисунке 1 представлены потоки информационного взаимодействия в компании в учетно-аналитической сфере.

Для создания единой информационной системы учета и аудита необходима автоматиза- ция этой сферы. Основными положительными аспектами применения автоматизации учета для развития единой информационной системы являются совершенствование процессов и повышение качества информации; усиление контрольной функции со стороны руководства организации и осуществление разграничения доступа к информации; возможность оперативного учета данных и оценки текущего финансового состояния хозяйствующего субъекта и перспектив его развития, а также расширение аналитических возможностей учета за счет применения нескольких стандартах.

Также новые возможности автоматизации учета для развития единой информационной системы заключаются в снижении временных затрат на осуществление учетных операций. Кроме того, автоматизация учета эвентуально приведет к снижению затрат труда сотрудников бухгалтерии и к росту его производительности.

При внедрении автоматизации учета и аудита важен подбор программного обеспечения. Информационные технологии позволяют совер-

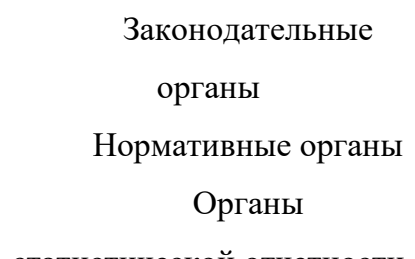

статистической отчетности

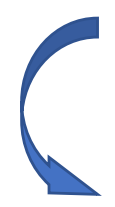

Дочерние

предприятия

Инвесторы и акционеры

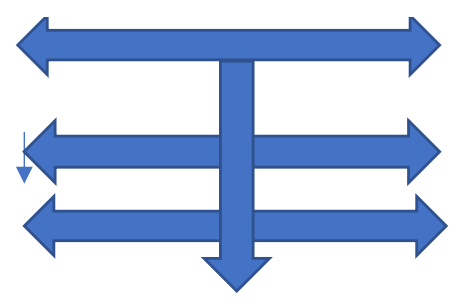

Предприятие

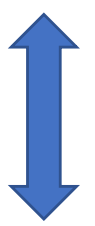

Сотрудники

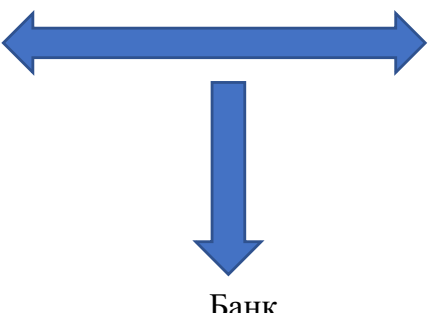

(текущий счет,

депозиты, ценные бумаги,

кредиты, инвестиции)
Контролирующие

органы

Налоговая инспекция

Пенсионный фонд

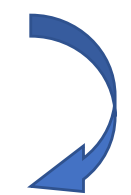

Средства массовой

информации

Потребители

Puc. 1. Потоки информационного взаимодействия в компании в учетно-аналитической сфере Источник: составлено авторами. 
шенствовать бухгалтерские программы, однако в нормативной базе отсутствует общепринятая их классификация. Программы различаются по функциям и по видам бухгалтерских операций. Основными программами являются: «Мини-бухгалтерия» для отчетности малого бизнеса с ограниченным объемом данных; «Интегрированная бухгалтерская система» с большим объемом информации; «Комплексная система бухгалтерского учета», нацеленная на самый широкий круг задач учета; «Корпоративные системы управления финансами и бизнесом», представляющие собой структуру компонентов и подсистему бухгалтерского учета.

Так, программа 1С: Бухгалтерия, дает возможность анализа и оценки информации по движению денежных потоков и осуществлению финансовых операций; компьютерная бухгалтерская программа «Инфо -Предприятие: Бухгалтерия» придает оптимальные свойства бухгалтерской отчетности в единой базе данных, учитывает специфику деятельности субъекта хозяйствования; программа «Парус - Предприятие» позволяет автоматизировано вести учет и анализ научно-исследовательских и опытно-конструкторских разработок хозяйствующего субъекта.

Особое место среди программных продуктов занимает программа «Мое дело», которая впервые в РФ позволила осуществлять учет и анализ деятельности субъектов хозяйствования, а также вести отчётность в облачном сервисе; производить расчет начисления заработной платы, составлять договоры, выставлять счета, оформлять акты; осуществлять расчет оплаты больничных листов и отпускных начислений, передавать отчетность в электронном виде.

На рисунке 2 отражены группы программ, применяемые в РФ в бухгалтерском учете и отчетности в рамках формирования единой информационной системы.

Для формирования единой информационной базы и автоматизации учета важно учитывать уровни программных продуктов, среди которых выделяют полный, высокий, средний, низкий.

Полный уровень включает целиком интегрированные системы; высокий уровень состоит из программных продуктов, которые поддерживают информационные системы учета и отчетности и другие системы; средний уровень программных продуктов автоматизации учета включает программные продукты для комплексной автоматизации бухгалтерского учета и отчетности; низкий уровень, соответственно, продукты для локальной автоматизации отдельных участков бухгалтерского учета и отчетности

Направлениями совершенствования автоматизации бухгалтерского учета является переход к полному уровню интеграции систем учета, что станет отправной точкой развития единой информационной системы; решение проблемы оптимизации информации бухгалтерской отчетности без потери ее качества и систематизация учетных процедур.

При решении задач развития учета, анализа и аудита в рамках единой информационной системы, как перспективного направления в условиях цифровизации, следует охарактеризовать информационные системы бухгалтерского

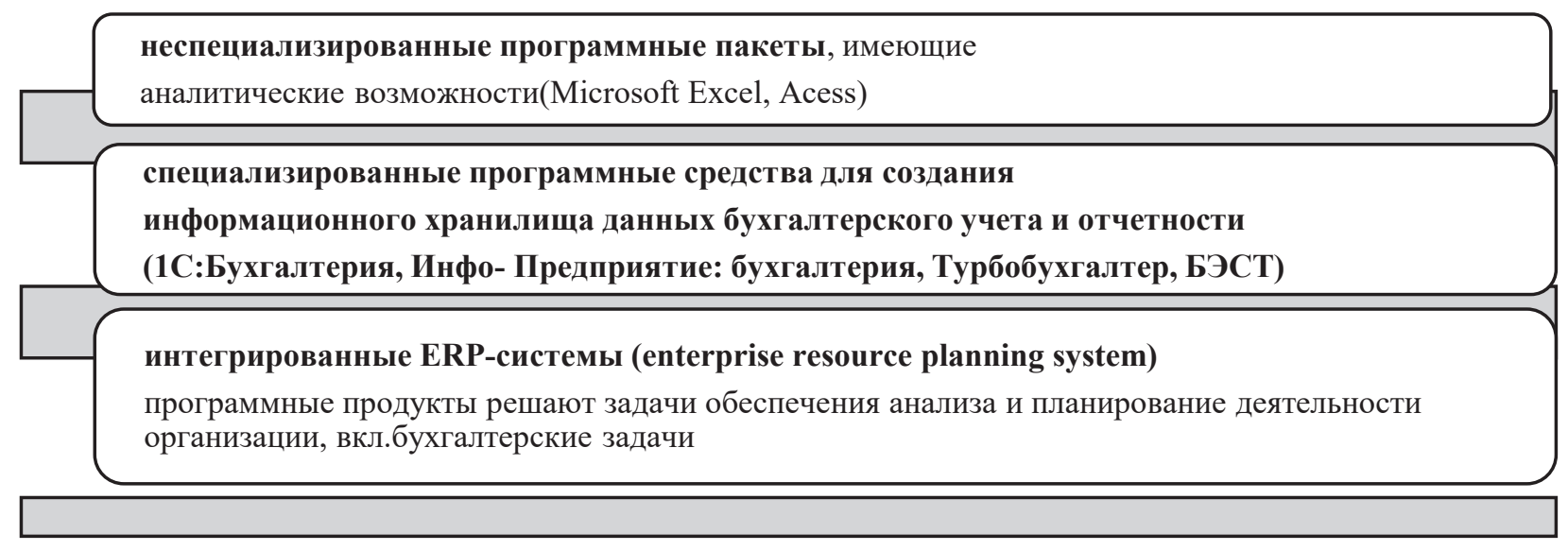

Puc. 2. Основные группы программ, применяемые в бухгалтерском учете и отчетности в рамках формирования единой информационной системы Источник: составлено авторами. 
Таблица 1. Характеристика информационных систем бухгалтерского учета в зависимости от масштаба деятельности субъекта хозяйствования

\begin{tabular}{|c|c|c|c|c|}
\hline \multirow{2}{*}{$\begin{array}{c}\text { Вид информационной } \\
\text { системы бухгалтерского } \\
\text { учета }\end{array}$} & \multirow{2}{*}{$\begin{array}{c}\text { Подвид информационной системы } \\
\text { бухгалтерского учета }\end{array}$} & \multicolumn{3}{|c|}{$\begin{array}{c}\text { Масштаб деятельности } \\
\text { субъекта хозяйствования }\end{array}$} \\
\hline & & Малые & Средние & Большие \\
\hline Несетевая технология & Локальная база & + & - & - \\
\hline \multirow[t]{3}{*}{ Сетевая технология } & $\begin{array}{l}\text { «файловый сервер», централизованная } \\
\text { бухгалтерская деятельности }\end{array}$ & - & + & - \\
\hline & $\begin{array}{l}\text { «клиент-сервер», централизованная } \\
\text { бухгалтерская деятельность }\end{array}$ & - & + & + \\
\hline & $\begin{array}{l}\text { «клиент-сервис», распределенная бух- } \\
\text { галтерская деятельность }\end{array}$ & - & - & + \\
\hline
\end{tabular}

Источник: составлено по материалам [2; 3; 4].

учета в зависимости от масштаба компании. Как видно из таблицы 1 , наблюдается прямая зависимость масштаба предприятия и интенсивности информационных потоков.

Для крупных предприятий характерен полный уровень программной продукции и автоматизации бухгалтерского учета во взаимосвязи с информационной системой хозяйствующего субъекта.

Источниками расширения возможностей учета, анализа и аудита служат информационно-цифровые технологии. Однако, на практике наблюдается недопонимание различий автоматизации, компьютеризации, информатизации и цифровизации, в результате одно понятие неправомочно подменяется другим.

Так, автоматизация заключается в переводе бухгалтерского учета, анализа и аудита в автоматический режим на основе компьютерной электронной вычислительной техники, с применением математических методов и возможностью хранения и обмена информацией в электронном виде.

Компьютеризация представляет получение оперативных данных в результате обработки информации и сосредоточение результатов в базах данных компьютеров с целью составления бухгалтерской отчетности.
Информатизация заключается в концентрации данных валидной, точной информации, актуальных данных в бухгалтерском учете, анализе и аудите, как в отдельных видах деятельности, так и частично пересекающихся.

Компьютерные технологии и программы позволяют увеличивать скорость взаимодействия в ходе реализаций функций учета и упрощать операции, но расширить возможности учета, анализа и аудита как единой системы на базе информационно - цифровых технологий, такие технологии в полной мере решить не смогут

Цифровизация изменяет бизнес-процессы на более сложном уровне работы с учетно-аналитической и контрольной информацией.

Как указано во «Всемирном обзоре реализации концепции «Индустрия 4.0» за 2016 г. [1], цифровизация в значительно большей степени вытесняет труд человека, чем простая автоматизация и компьютеризация. Цифровизация подразумевает не только использование программного обеспечения, но и коренное изменение в подходах к управлению и внешних коммуникациях.

Использование информационно-цифровых технологий позволит встроить учет, анализ и аудит в систему цифрового управления.

\section{Библиографический список}

1. Всемирный обзор реализации концепции «Индустрия 4.0» за 2016 г.- URL: https://www.pwc.ru/ru/ technology/assets/global_industry-2016_rus.pdf (дата обращения: 02.09.2019).

2. Мельник М.В. Модернизация учетно-контрольных и аналитических процессов в условиях цифровой экономики // Учет. Анализ. Аудит. - 2018. - № 3.- С.129-130.

3. Мельник М.В., Салин В.Н. Предпосылки эффективного развития цифровой экономики // Учет. Анализ. Аудит. - 2018. - № 5(6). - С.6-16. DOI: 10.26794/2408-9303-2018-5-6-6-16.

4. Рожнова О.В. Гармонизация учета, аудита и анализа в условиях цифровой экономики // Учет. Анализ. Аудит. - 2018. - № 3.- С.16-23.

5. Федеральный закон от 27 июля 2006 года № 149-Ф3 «Об информации, информационных технологиях и о защите информации» 